\title{
Effect of Counseling based on Sexual Self-Concept on the Sexual Health of Women in Reproductive Age
}

\author{
Tayebe Ziaei ${ }^{1}$, Halimeh Farahmand Rad ${ }^{2 *}$, Ghlomareza Roshandel ${ }^{3}$ and Masumeh Aval ${ }^{4}$ \\ ${ }^{1}$ Department of Reproductive Health and Counseling in Midwifery Research Center, Golestan University of Medical Sciences, Iran \\ ${ }^{2}$ Department of Counseling in Midwifery, Golestan University of Medical Sciences, Iran \\ ${ }^{3}$ Department of Gastroenterology and Hepatology Research Center, Golestan University of Medical Sciences, Iran \\ ${ }^{4}$ Department of Clinical Psychology, Golestan University of Medical Sciences, Iran
}

Submission: January 09, 2018; Published: March 19, 2018

*Corresponding author: Halimeh Farahmand Rad, Reproductive Health and Counseling in Midwifery Research Center, Golestan University of Medical Sciences, Gorgan, Iran, Tel: +98353599582; Email: Farahmand.rad@gmail.com

\begin{abstract}
Background: Sexual health is fundamental to the physical and emotional health and the basis of well-being of individuals, couples and families. The World Health Organization states that, having sexual health, pleasurable sexual life and sexual awareness are among human rights, and considers counseling as an important method to enter into discussion on sexuality of people. Individuals' sexual self-concept is an important factor that affects sexual health. The aim of this study was to determine the effect of counseling based on sexual self-concept on Women's sexual health.
\end{abstract}

Method: This interventional study was conducted on 59 reproductive age women. Data collection tools were the Female Sexual Function Index and sexual self-concept questionnaires. After compilation of the questionnaires by the two (intervention and control) groups, individual counseling based on sexual self-concept was conducted in the intervention group. A month after the intervention, the groups were asked to complete the questionnaires once more. Data analysis, with nonparametric, Spearman and Mann-Whitney tests, was performed through SPSS software version 16 .

Result: Women in the intervention group had the total score of sexual function $(P<0.0001)$, and the mean score in dimensions of sexual desire $(\mathrm{P}=0.02)$, sexual excitement $(\mathrm{P}=0.01)$ and orgasm $(\mathrm{P}<0.0001)$ showed statistically significant increase compared to before the intervention (counseling). But, in the control group no statistically significant differences in the dimensions was observed.

Conclusion: Sexual counseling based on sexual self-concept is affective in maintaining and improving sexual health of women, therefore, it can be referred to as one of the effective methods in sexual counseling.

Keywords: Sexual self-concept; sexual health; Reproductive age women

\section{Background}

Sexual health is fundamental to the physical and emotional health and the basis of well-being of individuals, couples and families. Sexual health is considered as a measure to determine the level of social and economic development in countries. The World Health Organization states that, having sexual health, pleasurable sexual life and sexual awareness are among human rights, and considers counseling as an important method to enter into discussion on sexuality of people. Individuals' sexual self-concept is an important factor that affects sexual health. It refers to understanding and conception of individuals from their sexuality. Therefore, counseling based on sexual self-concept can be effective in maintaining and improving sexual health. The aim of this study was to determine the effect of counseling based on sexual self-concept on Women's sexual health.

\section{Method}

This interventional study was conducted on 59 married women between 15 to 44 years old attending the health centers of Gorgon city, Iran who had met the Inclusion criteria. Data collection tools were the Female Sexual Function Index and sexual self-concept questionnaires. After compilation of the questionnaires by the two (intervention and control) groups, individual counseling based on sexual self-concept was conducted in the intervention group. A month after the intervention, the two 


\section{Global Journal of Reproductive Medicine}

groups were asked to complete the questionnaires once more. Then data analysis, with nonparametric, Spearman and MannWhitney tests, was performed through SPSS software version 16.

\section{Result}

The results showed that, women in the intervention group had the total score of sexual function $(\mathrm{P}<0.0001)$, and the mean score in dimensions of sexual desire $(\mathrm{P}=0.02)$, sexual excitement $(\mathrm{P}=0.01)$ and orgasm $(\mathrm{P}<0.0001)$ showed statistically significant increase compared to before the intervention (counseling). But, in the control group no statistically significant differences in any of the dimensions was observed.

\section{Conclusion}

Women's sexual function is considered as one of the key components of sexual health. The results of this study showed that, sexual counseling based on sexual self-concept is affective in maintaining and improving sexual health of women, therefore, it can be referred to as one of the effective methods in sexual counseling.

\section{Introduction}

The World Health Organization [1] has defined sexual health as a status of physical, mental, emotional, psychological and social health in sexuality, and stated that, having and maintaining sexual health must be considered as human's sexual right. Sexual health is an important component of well-being and health [2]. Lack of sexual health in addition to affecting interpersonal relationship, leads to undesired consequences such as inability to make a healthy and satisfactory sexual relation with sexual partner, which itselfleads to undesired physical, mental and social consequences in couples. Thus, sexual health plays a crucial role in the quality of marital life [3-5]. Lack of sexual health in women leads to psychological disorders such as; depression, anxiety, mood swings, sexual fear and sexual dysfunction [6]. One of the key components of people's sexual health is sexual function, which unfortunately, is the most common sexual health problem in people. Studies have shown that, sexual function at any level is able to affects women's sexual satisfaction, and causes degrees of stress in them [7]. On the other hand, women's sexual function is influenced by physical and psychological factors. Among the common factors that can threaten sexual function is the understanding or conception of individuals from their sexuality. For instance, women who think they are not attractive for their husbands are at the risk of developing sexual disorder twice the time than women who think the opposite $[8,9]$. Understanding and conception of people from their sexuality is called sexual self-concept, and this psychological factor consists of positive and negative dimensions [10] Positive sexual self-concept regulates behaviors and excitements in such way that, women with positive self-concept experience positive sexual behaviors and excitements.

On the other hand, women with negative self-concept have less successful interpersonal relationships and fewer sexual experiences and sexual satisfaction, and usually have a negative and conservative attitude towards sexual issues. These women (with negative sexual self-concept) when asked to predict their future sexual plan, they show a great deal of uncertainty and pessimism [11,12]. Accordingly, assessing sexual selfconcept as a tool to determine the status of sexual interaction with others (interpersonal) and intra-personal status can have a crucial role in people's sexual health, so in people, who need sexual intervention, the counselor or therapist can use their sexual self-concept as a tool to examine their sexual health [13]. Furthermore, whereas sexual self-concept, due to the past personal experiences, is different from person to person and because of the need to preserve the principle of confidentiality [14], self-concept as a method of sexual counseling, is effective in maintaining or improving the sexual health in individuals.

\section{Materials and Methods}

This interventional study was conducted on 59 married 15 to 44 years old women attending health centers of Gorgan city, Iran to receive healthcare services. Conventional sampling method was used to select the women who were later randomly divided into two groups (intervention and control groups). The inclusion criteria of the study were; willingness to participate in the study, having at least primary school education and higher, having passed over 6 month since last birth delivery, having no history of adverse event (such as death of loved ones or accidents causing disability) in the last three months, having no chronic mental/ physical disease such as vaginal infection, having no severe marital conflicts, not being pregnant or plan to get pregnant during the study, not taking anti-anxiety and antidepressants medication, not being drug addict(husband and wife), and not being pregnant for more than 5 times. The exclusion criteria were; immigration of samples during the study, couples' decision to separate from each other, occurrence of adverse event (death of loved ones or accident leading to disabilities, etc.), and diagnosis of acute or chronic sexual problems due to physical or mental reasons during the study.

Data collection tools included a form and two questionnaires, the demographic form and, the Persian Female Sexual Function Index questionnaire, consisted of 19 questions with 5 options. The validity and reliability of the questionnaire was confirmed in the study of Mohammadi et al. with Cronbach's Alpha of 0.70 and above in which, the sexual function in six dimensions including sexual desire (first and second question with scores of 1 to 5), sexual excitement (3 to 6 questions), vaginal lubricant ( 7 to 10 questions), orgasm (11 to 13 questions), sexual satisfaction ( 14 to 16 questions with the scores 1-5) and sexual pain (17 to 19 questions with the scores 1-5) were assessed (14) and the Persian multidimensional questionnaire on self-concept with 18 domains and 78 items. The validity and reliability of the Persian multidimensional questionnaire on self-concept with Cronbach's Alpha of 0.88 and reliability index greater than 0.70 was also confirmed in the study of Ziaei et al. [15]. In this study, from 


\section{Global Journal of Reproductive Medicine}

the 23 questions asked, five dimensions of sexual self-concept including sexual fear (Q: 5-9-13- 18-23), sexual anxiety (Q: 1-610-14-19), sexual self-efficacy (Q: 2-7-15-20), sexual satisfaction (Q: 4-8-12-17-22) and sexual self-esteem (Q: 3-11-16-21) a) were used [15].

All participants completed the demographic questionnaire form. Women who were in the intervention group underwent individual counseling based on sexual self-concept. Short-term counseling session with eclectic approach was conducted for 45 minutes by a midwifery consultant under the supervision of a clinical psychologist with MSc degree. The consultation process with sexual self-concept approach, based on scores in each area of sexual function was started and continued with non-verbal observation (behavioral and emotional) and verbal review during the interview process. The progress was assessed and sexual function based on scores obtained from the questionnaire was evaluated. Positive and negative points were identified through sexual self-concept questionnaire, which put forward two conditions:

a. The existing condition was approved, and

b. Problems and concerns were identified so they could be responded to, and if the problems were too many, they were prioritized [16]. If further session was required or the participant asked for further session, a time for the next meeting was set up. One month after the consultation, women in both groups were called again to complete the questionnaire once more. All subjects signed consent from to participate in the study. The participants had right to withdraw from the study if their wished to do so.

\section{Ethical considerations}

i. Written consent was obtained from the entire participant before taking part in this study.

ii. All participants had right to withdraw from the study at any time if they wished to do so.

iii. The confidentiality principal was preserved by; keeping all the participants' information confidential, using anonymous questionnaire and a code was given to each questionnaire instead of name, and conducting the counseling individually and giving the researchers' telephone number to the participants to ask any question any time.

iv. This study had benefits for the sample as it was included the consultation on sexual functioning in order to improve it.

v. The results of the project were effective in promoting sexual health of the participants.

vi. An informed consent was obtained from the spouses of the participants in intervention group before the taking part in counseling sessions'.

vii. The counselors and the participants belonged to same gender. Statistical analysis was carried out on the data collected from 59 participants. Demographic data was analyzed using parametric test and non-parametric test (Wilkekson, Spearman and Mann-Whitney) according to the research objectives through SPSS software version 16.

\section{Results}

The results of Chi-square test and t-test showed no statistically significant differences between the intervention and control groups in terms of demographic variables such as age, occupation and education of the spouses, mode of birth delivery, contraception way, breastfeeding condition, and parental style. Mann-Whitney test showed no statistically significant difference between the two groups in terms of average female sexual function scores before the intervention in various fields. The result of Wilkerson showed a statistically significant increase in the overall score of sexual function in the intervention group $(\mathrm{P}<0.0001)$ compared to before the intervention, and also a significant increase was observed in the dimensions of; sexual desire $(\mathrm{P}<0.02)$, sexual excitement $(\mathrm{P}<0.01)$, orgasm $(\mathrm{P}<0.000)$ in the intervention group after the intervention. But, in the control group, no significant increase was seen in any of these dimensions (Table 1). Results of the same test also showed in the intervention group, the mean score of dimensions of sexual selfconcept after the consulting showed a significant decrease in the dimension of sexual anxiety $(\mathrm{P}<0.01)$, and a significant increase in the dimensions of sexual self-esteem $(\mathrm{P}<0.04)$ and sexual satisfaction $(\mathrm{P}<0.03)$. But, no significant difference was observed in any of these dimensions in the control group (Table 2).

Table 1: comparing the dimension's score of sexual function in two groups before and after intervention.

\begin{tabular}{|c|c|c|c|c|c|c|}
\hline & \multicolumn{3}{|c|}{ Intervention } & \multicolumn{3}{|c|}{ Control } \\
\hline & Before & After & \multirow[b]{2}{*}{ P-value } & Before & After & \multirow[b]{2}{*}{ P-value } \\
\hline & $\begin{array}{l}\text { Mean/ standard } \\
\text { error }\end{array}$ & $\begin{array}{c}\text { Mean/ standard } \\
\text { error }\end{array}$ & & $\begin{array}{l}\text { Mean/ standard } \\
\text { error }\end{array}$ & $\begin{array}{l}\text { Mean/ standard } \\
\text { error }\end{array}$ & \\
\hline \multirow{2}{*}{ Sexual desire } & 6.15 & 7 & 0.02 & 6.57 & 6.51 & \multirow{2}{*}{0.92} \\
\hline & 1.4 & 1.16 & & 1.32 & 1.03 & \\
\hline \multirow{2}{*}{ Sexual excitement } & 13.84 & 15.46 & 0.01 & 14.15 & 14.71 & \multirow{2}{*}{0.12} \\
\hline & 2.96 & 2.76 & & 2.9 & 2.55 & \\
\hline \multirow{2}{*}{ Sexual lubricant } & 16.58 & 17.53 & 0.06 & 17.03 & 16.96 & \multirow{2}{*}{0.72} \\
\hline & 2.82 & 2.62 & & 2.9 & 2.05 & \\
\hline
\end{tabular}




\begin{tabular}{|c|c|c|c|c|c|c|}
\hline \multirow{2}{*}{ Orgasm } & 11.92 & 13.34 & 0 & 12.42 & 12.51 & \multirow{2}{*}{0.98} \\
\hline & 2.13 & 1.23 & & 1.88 & 1.78 & \\
\hline \multirow{2}{*}{ Sexual satisfaction } & 12.57 & 13.61 & 0.06 & 13.12 & 13.09 & \multirow{2}{*}{-0.07} \\
\hline & 2.38 & 1.91 & & 2.17 & 2.11 & \\
\hline \multirow{2}{*}{ Sexual pain } & 10.96 & 11.73 & 0.4 & 11.75 & 12.39 & \multirow{2}{*}{0.12} \\
\hline & 2.7 & 2.42 & & 2.83 & 2.57 & \\
\hline \multirow{2}{*}{ Total score } & 72.43 & 78.69 & 0 & 75.06 & 76.12 & \multirow{2}{*}{0.39} \\
\hline & 11.44 & 7.85 & & 8.95 & 7.83 & \\
\hline
\end{tabular}

Table 2: comparing the dimension's score of sexual self-concept in two groups before and after intervention.

\begin{tabular}{|c|c|c|c|c|c|c|}
\hline & \multicolumn{3}{|c|}{ Intervention } & \multicolumn{3}{|c|}{ Control } \\
\hline & Before & After & \multirow[b]{2}{*}{ P-value } & Before & After & \multirow[b]{2}{*}{ P-value } \\
\hline & $\begin{array}{c}\text { Mean/Standard } \\
\text { Error }\end{array}$ & $\begin{array}{c}\text { Mean/Standard } \\
\text { Error }\end{array}$ & & $\begin{array}{c}\text { Mean/Standard } \\
\text { Error }\end{array}$ & $\begin{array}{c}\text { Mean/Standard } \\
\text { Error }\end{array}$ & \\
\hline \multirow{2}{*}{ Sexual anxiety } & 3.53 & 2.11 & 0.01 & 1.54 & 0.78 & \multirow{2}{*}{0.09} \\
\hline & 4.19 & 2.73 & & 3.21 & 1.53 & \\
\hline \multirow{2}{*}{$\begin{array}{l}\text { Sexual self- } \\
\text { efficacy }\end{array}$} & 12.15 & 12.61 & 0.43 & 12.87 & 13.51 & \multirow{2}{*}{0.19} \\
\hline & 3.09 & 2.29 & & 3.47 & 2.93 & \\
\hline \multirow{2}{*}{ Sexual self-esteem } & 10.53 & 11.76 & 0.04 & 11.15 & 12.24 & \multirow{2}{*}{0.17} \\
\hline & 3.25 & 3.01 & & 4.07 & 2.87 & \\
\hline \multirow{2}{*}{ Sexual satisfaction } & 14.5 & 15.92 & 0.03 & 15.21 & 16 & \multirow{2}{*}{0.39} \\
\hline & 4.38 & 3.4 & & 3.66 & 3.52 & \\
\hline \multirow{2}{*}{ Sexual fear } & 4.88 & 4.19 & 0.3 & 4.06 & 3.78 & \multirow{2}{*}{0.57} \\
\hline & 2.73 & 3.12 & & 3.12 & 3.33 & \\
\hline \multirow{2}{*}{ Total score } & 45.61 & 46.61 & 0.25 & 45.56 & 46.28 & \multirow{2}{*}{0.51} \\
\hline & 6.49 & 6.35 & & 7.16 & 7.55 & \\
\hline
\end{tabular}

\section{Discussion}

The present study showed that, counseling based on sexual self-concept has a positive effect on maintaining and improving sexual function, which is consistent with the findings of Markus study (1987) which concluded that, dimensions of sexual selfconcept as an important component of individuals' cognitive system, have active and dynamic nature and are able to change, and can influence the function of individuals and also can be influenced with it [17]. Also in this study, the mean score of dimensions of sexual self-concept after consulting showed a statistically significant decrease in the dimension of sexual anxiety and an increase in the dimensions of sexual self-esteem and sexual satisfaction. The findings of Hensel [18] which showed, the more we reduce sexual anxiety, the more sexual health improves, is also in line with the results of this study. These results are consistent with the findings of Reissing et al. [19] study which indicated that, improving and changing sexual self-concept is immensely effective in improving natural sexual function and preventing sexual dysfunction. Hucker et al. [20] observed that, sexual self-concept potentially increases women's sexual function. Chen et al. [21] showed that, strengthen sexual self-concept in women improves their sexual health. The results of Andersen et al. [22] suggested that, women with improved sexual self-concept have a better and are more successful sexual function $[23,24]$.

\section{Conclusion}

The present study aimed to determine the effect of counseling based on sexual self-concept on sexual health of women in reproductive age who attended health centers in Gorgan a city in Iran. This study showed that, counseling based on sexual selfconcept can affect the sexual function of women in reproductive age. It maintains and improves the women's sexual function by changes the dimensions of sexual self-concept. On other words, the results showed the importance of counseling based on sexual self-concept on improving sexual function in people particular women in childbearing age. Since all dimensions of sexual function in this study were not significantly affected by sexual self-concept counseling, it is suggested that, it would be better to conduct such counseling on each of the dimensions of sexual function separately in order to better determine the effects of such counseling on sexual health.

\section{Acknowledgement}

Hereby, I would like to thank Gorgan University of Medical Sciences and its expert personnel for their help and support to 


\section{Global Journal of Reproductive Medicine}

conduct this study with approval number: GOUMS.REC 1394, 69. Financial Support: Golestan University of Medical Science

\section{Conflicts of Interest}

The authors report no conflicts of interest. The authors alone are responsible for the content and writing of the paper.

\section{Limitations}

The most important limitations in this project were:

i. The need to strengthen life skills of the participants (in this study we did not have enough time for it),

ii. The questionnaires were completed through selfreporting, and

iii. Geographical limitation to generalize the findings.

\section{Recommendations}

Counseling based on sexual self-concept as a new method of sexual counseling should be taught to midwifery students to maintain and improve sexual health of women. This method of counseling should be used by existing midwives to assess, maintain and improve sexual function of their female clients. To examine the effects of counseling based on sexual self-concept (each of the positive and negative dimensions) on sexual function (one of the dimensions) of different groups of women and men in different ages and periods such as pregnancy and menopause.

\section{References}

1. Organization WHO (2010) Developing sexual health programmers: a framework for action, Geneva, Switzerland.

2. Organization WHO (2006) Defining sexual health: report of a technical consultation on sexual health. Geneva, Switzerland.

3. Safarinejad M (2006) Female sexual dysfunction in a population-based study in Iran: prevalence and associated risk factors. Int J Impot Res 18(4):382-395.

4. Farahmand M, Mihrabi YH, Abedini M (2012) Sexual dysfunction and its risk factors: population-based study among women in urban areas of four provinces 11(6): 869-875.

5. Laumann EO, Paik A, Glasser DB, Kang JH, Wang T, et al. (2006) A crossnational study of subjective sexual well-being among older women and men: findings from the Global Study of Sexual Attitudes and Behaviors. Arch Sex Behav 35(2): 145-161.

6. Steinberg, Jeff West, Daniel J (2020) Depression as a major mental health problem for the behavioral health care industry. Journal of Health Sciences Management and Public Health 1: 44-49.

7. Stephenson KR, Meston CM (2015) Why is impaired sexual function distressing to women? The primacy of pleasure in female sexual dysfunction. J Sex Med 12(3): 728-737.
8. Ebrahimi M, Haghighat S, Mehrdad N, Olfatbakhsh A (2015) Sexual Dysfunction in Breast Cancer: A Case-Control Study. Archives of Breast Cancer. 2(1): 15-20.

9. Jahanfar Ds, Nejad DMM (2014) A course on sexual disorders In: Jameenegar, et al. (Eds.) Bishe publitioer pp. 36-116.

10. Snell WE (1998) Multidimensional Sexual Self-Concept Questionnaire Handbook of sexuality-related measures pp. 521-524.

11. Andersen BL, Cyranowski JM (1994) Women's sexual self-schema Journal of personality and social psychology 67(6): 1079.

12. Mueller K, Rehman US, Fallis EE, Goodnight JA (2016) An Interpersonal Investigation of Sexual Self-Schemas. Arch Sex Behav 45(2): 281-290.

13. Pai HC, Lee S, Yen WJ (2012) The effect of sexual self-concept on sexual health behavioral intentions: a test of moderating mechanisms in early adolescent girls. J Adv Nurs 68(1): 47-55.

14. Michel RGaM (2011) Consultation and guidance context, persian translate. Tehran, Roshd publisherer pp. 644-661.

15. Ziaei T, Khoei EM, Salehi M, Farajzadegan Z (2013) Psychometric properties of the Farsi version of modified Multidimensional Sexual Self-concept Questionnaire. Iran J Nurs Midwifery Res 18(6): 439-445.

16. Basson R, Leiblum S, Brotto L, Derogatis L, Fourcroy J, et al. (2004) Revised definitions of women's sexual dysfunction. J Sex Med 1(1): 4048.

17. Markus H, Wurf E (1987) The dynamic self-concept: A social psychological perspective. Annual review of psychology 38(1): 299337.

18. Hensel DJ, Fortenberry JD, O'Sullivan LF, Orr DP (2011) The developmental association of sexual self-concept with sexual behavior among adolescent women. J Adolesc 34(4): 675-684.

19. Reissing ED, Laliberté GM, Davis HJ (2005) Young woman's sexual adjustment: The role of sexual self-schema, sexual self-efficacy, sexual aversion and body attitudes. Canadian Journal of Human Sexuality 14(3-4): 77-85.

20. Hucker A, Mussap AJ, McCabe MM (2010) Self-concept clarity and women's sexual well-being. Canadian journal of human sexuality 19(3): 67-77.

21. Li Cc, Rew L, Chen L (2015) Factors affecting sexual function: A comparison between women with gynecological or rectal cancer and healthy controls. Nursing \& health sciences 17(1): 105-111.

22. Layman EO, Paik A, Rosen RC (1999) Sexual dysfunction in the United States: prevalence and predictors. Jama 281(6): 537-44.

23. Faghihzadeh S (2008) Credit Persian version of the Female Sexual Function Index-FSFI as the Female Sexual Function Index 7(1): 269278.

24. Organization WHO (2006) Reproductive Health Indicators: Guidelines for their generation interpretation and analysis for global monitoring. 

(C) Commons Attribution 4.0 License

BY DOI: $10.19080 /$ GJORM.2018.03.555622
Your next submission with Juniper Publishers will reach you the below assets

- Quality Editorial service

- Swift Peer Review

- Reprints availability

- E-prints Service

- Manuscript Podcast for convenient understanding

- Global attainment for your research

- Manuscript accessibility in different formats

( Pdf, E-pub, Full Text, Audio)

- Unceasing customer service

Track the below URL for one-step submission https://juniperpublishers.com/online-submission.php 